\title{
Ajuste da orientação de placas solares com técnicas de modelagem e sua influência na eficiência energética
}

DOI: $10.30609 /$ JETI.2018-6567

\author{
João P. K. Miranda ${ }^{1}$, Lucas E. O. Aparecido ${ }^{1}$, \\ Guilherme B. Torsoni ${ }^{1 *}$
}

1IFMS - Instituto Federal do Mato Grosso do Sul, Navirai, MS, Brasil

\section{Resumo}

Com o vasto crescimento da utilização de energia elétrica tanto residencial quanto industrial, viu-se a necessidade de implantação de outras formas de geração de energia renovável, principalmente a energia solar, que converte a luz do sol em energia elétrica. Estudos da viabilidade da implantação de placas solar residenciais e industriais têm sido realizados para se verificar se essas fontes de geração de energia são razoáveis do ponto de vista econômico. O desempenho de uma placa solar é altamente influenciado por sua orientação tanto azimutal quanto a inclinação. Isso se deve ao fato de que tanto a orientação quanto o ângulo de inclinação alteram a radiação solar que atinge a superfície do coletor. Esse trabalho afere esses parâmetros de orientação, aprimorando o processo de geração de energia pela determinação de uma inclinação ótima das placas tanto em relação ao azimute quanto em relação ao ângulo solar. A inclinação se mostrou diferente dos valores utilizados comercialmente na região de Naviraí. As orientações e o azimute que proporcionou a maior eficiência energética foram de $12^{\circ} 28^{\prime}$ e $50^{\circ} \mathrm{O} 1^{\prime}$, respectivamente. Assim, houve um aumento do desempenho das placas instaladas com a aplicação desse método, em $16 \%$ maior quando se comparada com placas instaladas pela orientação utilizada comercialmente.

Palavras-Chave: Modelagem, Eficiência energética, placas solares 


\section{1.- Introdução}

O planeta terra tem uma inclinação de $23^{\circ} 27^{\prime}$ em relação ao Equador Celeste [1], chamada obliquidade da eclíptica. Devido a isso, temos as estações do ano e a variação da inclinação solar incidida na terra em decorrência de diferentes Latitudes. Com isso a distância da Terra ao Sol varia somente 3\% no ano, sendo mais próxima do Sol (periélio) entre 4 a 7 de janeiro e mais afastado (afélio) entre 4 e 7 de julho (salvo os anos bissextos) [2]. A inclinação e distância em relação ao sol influenciam diretamente a radiação solar, sendo a mesma descrita pelo efeito fotoelétrico.

O efeito fotoelétrico descreve que os fótons incidentes sobre o material estão diretamente relacionados a quantidade de energia gerada [3]. A eficiência de conversão de energia de uma célula solar $(\varepsilon)$, é a porcentagem de energia convertida (a luz absorvida para geração de energia elétrica). Este termo é calculado usando a relação do ponto de potência máxima, Pm, dividido pela irradiação de luz de entrada, E (W/m2) e a área da superfície da célula solar Ac (m2), Equação 1 [4].

$$
\varepsilon=\frac{P_{m}}{E \cdot A_{c}}
$$

A inclinação das placas solares, para uma maior transformação de energia, resulta em uma orientação onde os raios solares devem incidir sobre a placa solar perpendicularmente (sombra zero), obtendo uma maior área de incidência solar $[5,6]$.

Atualmente, existem diversas orientações das placas solares disponíveis na literatura e com os diversos dados de inclinações solares para o território brasileiro fornecida por diversas fontes, uma forma de calcular a inclinação do sol ( $\delta$ em graus) pelos dias do ano (n), Equação 2 [7]:

$$
\delta=23,45 \sin \left(\frac{2 \pi(284+n)}{365}\right)
$$

0 método comercial utilizado é calculado pelo ângulo de inclinação igual à latitude do local de instalação e o azimute $(\theta)$ (Figura 1) sempre para direção Norte. Estes métodos apresentam alguns erros e uma maneira de amenizar esses erros é por meio dos ajustes dos modelos de simulação [8-11-12]. 


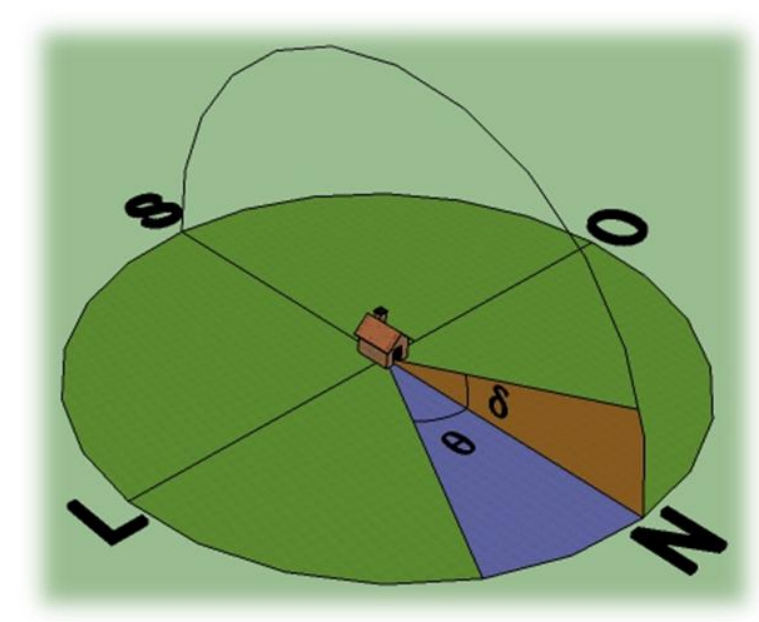

Figura 1: Esquema de medida do azimute $(\theta)$ e da inclinação solar $(\delta)$.

A deficiência de dados para a região de Naviraí torna a decisão das orientações das placas solares complexas e isso se torna fundamental para maximizar a geração solar fotovoltaica do sistema instalado. Com esse intuito, objetivou-se por meio deste trabalho avaliar se as orientações (azimute e inclinação) das placas solares comercialmente utilizadas são as que realmente proporcionam a maior eficiência energética. E ainda calcular a eficiência máxima a partir de medidas de sombra zero (eficiência máxima).

\section{2.- Materiais e Métodos}

O experimento foi realizado no IFMS campus de Naviraí, localizado na Latitude $23^{0} 04^{\prime}$ 'S e Longitude $54^{0} 12^{\prime} \mathrm{W}$ (Figura 2).

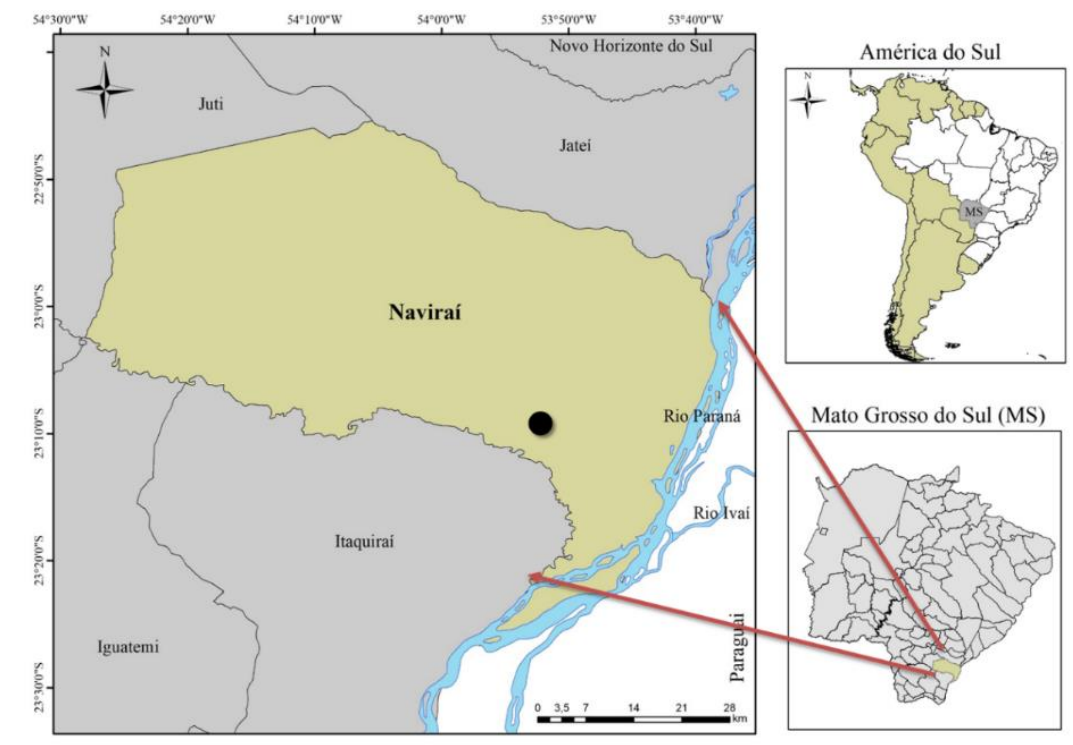

Figura 2: Localização geográfica da região de Naviraí, Sul do Mato Grosso do Sul. 
As aferições foram realizadas utilizando uma placa solar, retirada de carregador solar para celular, com uma tensão máxima de $6 \mathrm{~V}$ e corrente de $4000 \mathrm{~mA} / \mathrm{h}$. A placa foi acoplada a um suporte, feito em uma impressora 3D GTMax3D Pro Core $\mathrm{H} 4$ + com material plástico de poliácido láctico (PLA), que proporcionava um ajuste na orientação do eixo de referência (Figura 3a). 0 sistema de medidas compõe de um multímetro digital Hikari HM1000, para medida de tensão (Figura 3b).

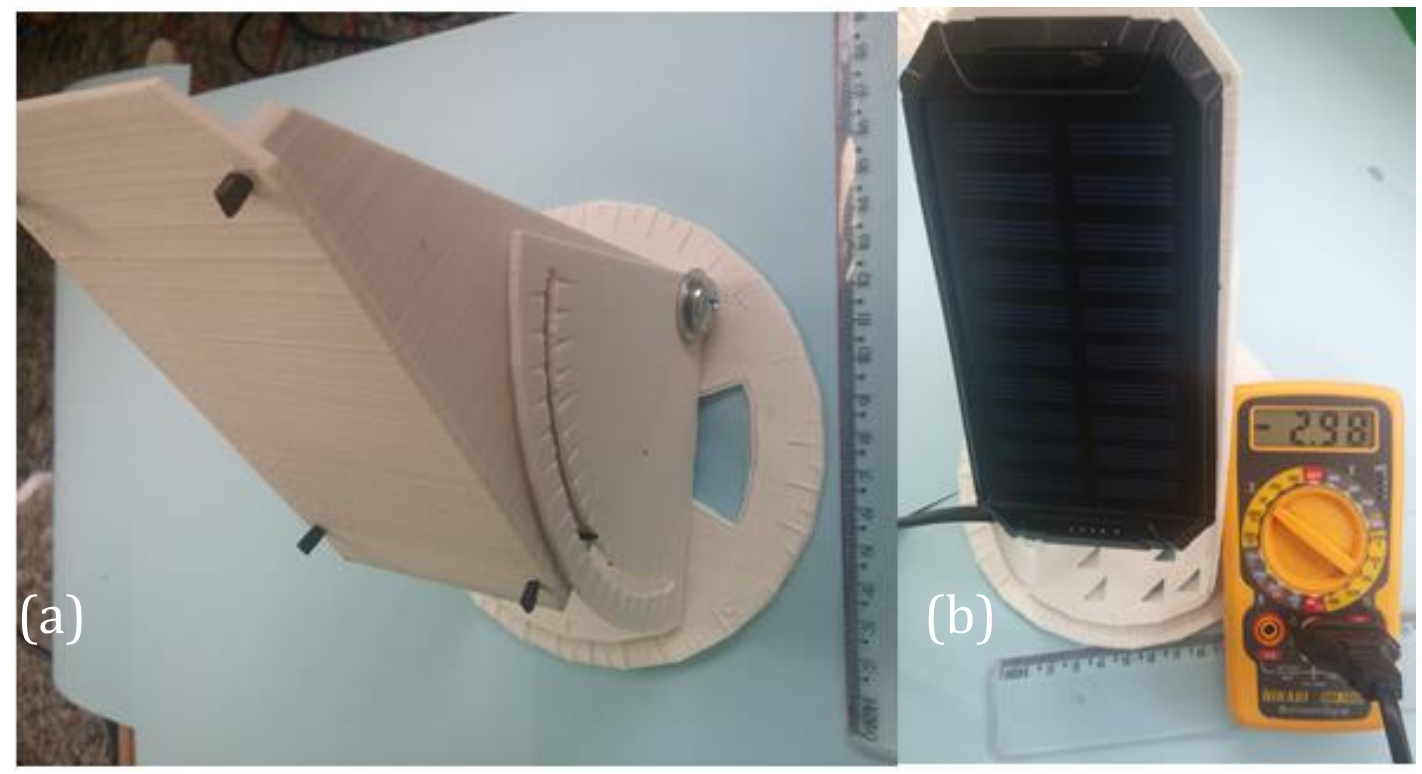

Figura 3: (a) Suporte produzido em uma impressora 3D, (b) Sistema de medidas montado.

Foram aferidas tensões nas inclinações de 67ำ e 60ㅜ, com relação a horizontal. Também foram aferidas as tensões em sombra zero (ausência de sombras - incidência perpendicular), para comparar como o padrão. Vale a pena ressaltar, que em sombra zero, o azimute pode variar em relação ao norte. As aferições foram realizadas durante três vezes ao dia, nos horários de $9 \mathrm{~h}: 20 \mathrm{~min}, 11 \mathrm{~h}: 40 \mathrm{~min}$, e às $15 \mathrm{~h}: 20 \mathrm{~min}$, diariamente durante o decorrer de um ano.

Com os dados coletados foram aplicados testes estatísticos de posição (média). Também foram ajustados modelos de regressões não lineares (Sigmoide e Gaussiano) usando o Solver do Excel.

\section{3.- Resultados e Discussão}

Com base nos dados coletados, foram feitas as análises das médias da inclinação e do Azimute, com relação a horizontal e a direção Norte respectivamente. No inverno notou- 
se que o azimute para as 9:20 e 15:20 se aproximaram nitidamente do Norte, enquanto que no verão, ambos demonstraram azimutes elevados. Por sua vez, para o azimute das 11:40 não houve uma grande variação no decorrer do ano (Figura 4.a). Nos meses de Novembro a Fevereiro notou-se uma maior inclinação, sendo valores maiores que $50^{\circ}$ para os horários de 09:20 e 15:20h e $60^{\circ}$ para 11:40h, devido ao sol estar no hemisfério de verão as alturas do mesmo são maiores, os dias mais longos e há maior intensidade radiação solar (Figura 4.b). Por sua vez, para os meses de Junho a Agosto foi encontrado um ponto de mínimo, $45^{\circ}$, $57^{0}$ e $29^{0}$ para os horários 09:20,11:40 e 15:20h, respectivamente, devido ao hemisfério de inverno, e consequentemente as alturas são menores e os dias mais curtos.

O ajuste da trajetória solar na média anual com relação aos horários (Figura 5) demonstrou que a linha do Azimute apresenta uma tendência Sigmoide (Equação 3), sendo que a maior taxa de crescimento foi de $62^{\circ}$ e ocorreu as $13: 26 \mathrm{~h}$. No início e final do dia o azimute resultou em uma orientação Leste e Oeste, respectivamente. A orientação Norte, que é a orientação padrão comercial, ocorreu as 13:35h.
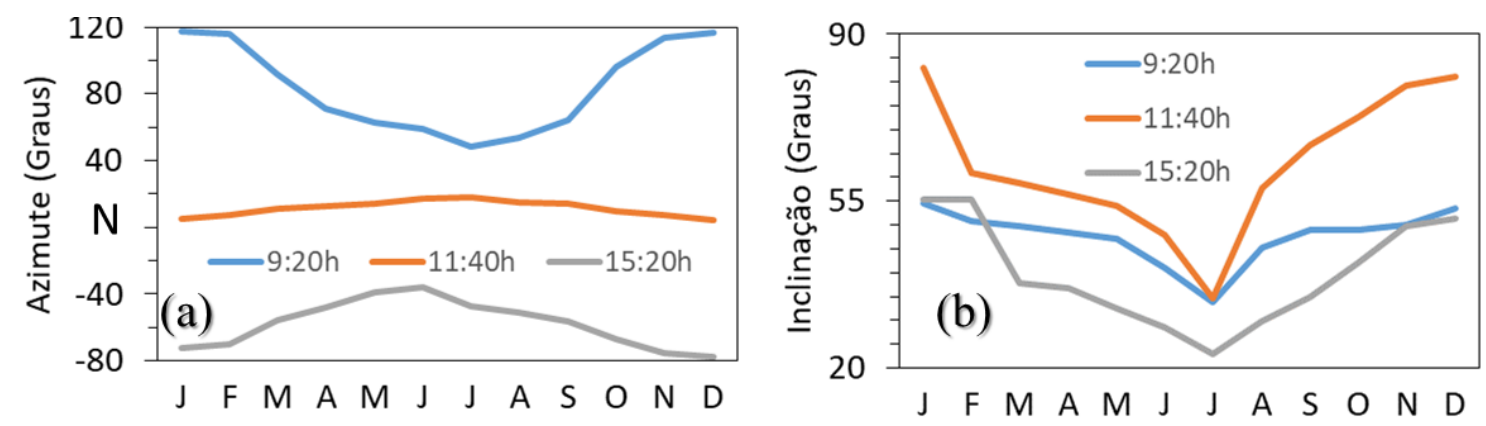

Figura 4: (a) Média do Azimute mensal com relação ao Norte, (b) da Média de Inclinação com relação Horizontal.

$$
A_{Z}=91,07+\frac{91,07+96,19}{1+\left(\frac{H}{0,56}\right)^{0,05}}
$$

Onde, Az é o azimute (graus) e $\mathrm{H}$ a hora em decimal.

A tendência da curva de inclinação com relação a horizontal foi ajustada pela curva Gaussiana (Equação 4).

$$
I_{n}=-90,59+\frac{93,66 \cdot e^{\frac{-4 \cdot \ln (2)(H-0,50)^{2}}{0,49^{2}}}}{0,49 \sqrt{\frac{\pi}{4 \cdot \ln 2}}}
$$


Onde, In é a inclinação (graus) e H a hora em decimal.

A maior inclinação (pico) da placa solar ocorreu as 12:12h com um valor de $62^{0} 48^{\prime}$ com relação a horizontal (Figura 5). 0 ajuste da curva se demostrou acurado uma vez que o início e término do dia, também conhecido como nascer e pôr do sol, foi conveniente com os horários pré-definidos pelo INPE. 0 modelo ajustado evidenciou que os horários de nascer e pôr do sol ocorrem as 06:08h e 18:12h, respectivamente.

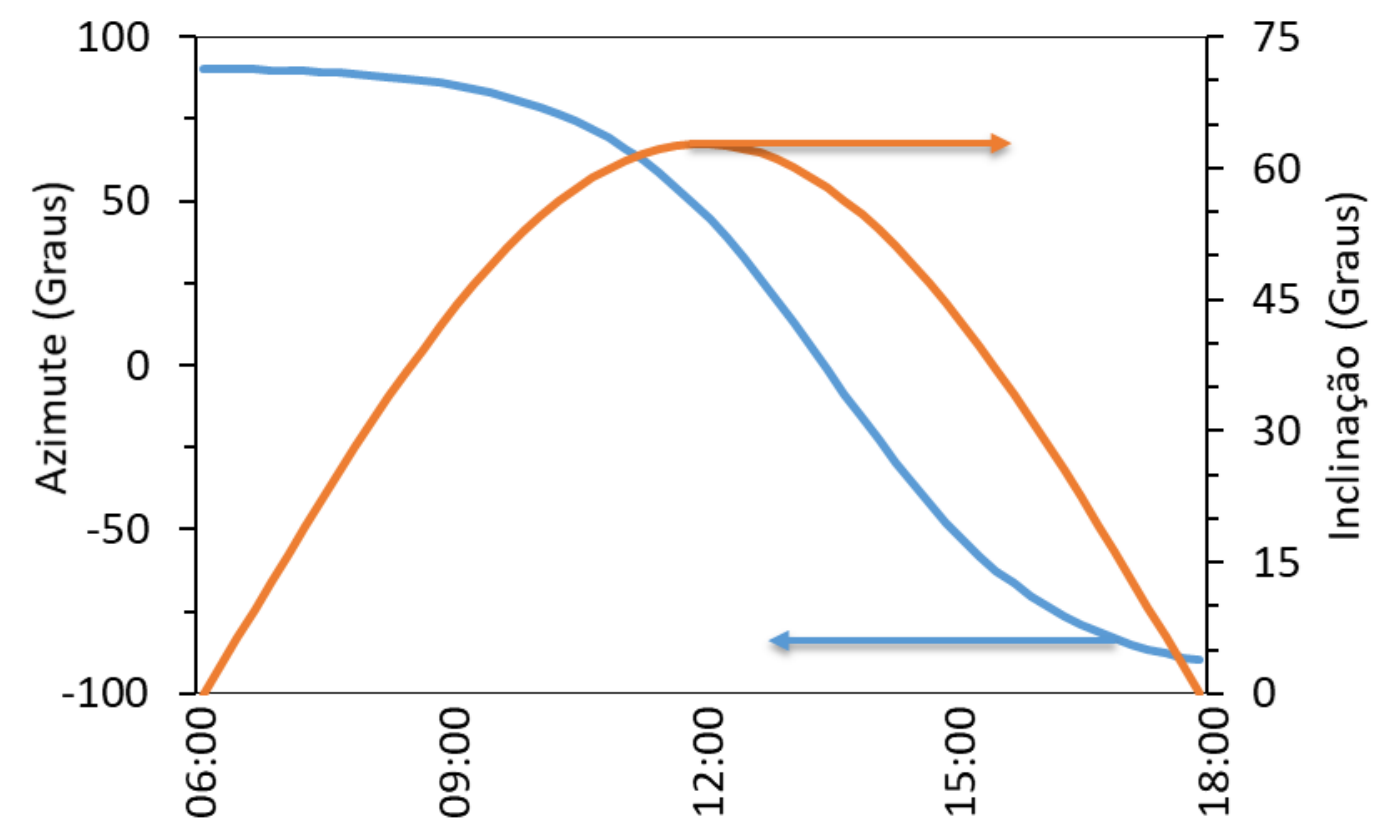

Figura 5: Média anual do azimute e da inclinação solar, no decorrer de um ano em função dos horários de um dia.

A média dos dados obtidos na condução do experimento (Tabela 1) foram diferentes dos valores que são utilizados comercialmente7. Os valores de azimute ideal foram de $12^{0} 28^{\prime}$ e de inclinação foram de $50^{\circ} 01^{\prime}$, valores esses que acarretaram uma eficiência de $16 \%$ na geração de energia, o que pode ser considerada um grande ganho financeiro com o passar dos anos. 
Tabela 1: Média anual para Azimute e Inclinação, para diferentes horários.

\begin{tabular}{|l|l|l|}
\hline & Azimute (Graus) & Inclinação (Graus) \\
\hline $9: 20 \mathrm{~h}$ & $84^{0} 12^{\prime}$ & $47^{0} 38^{\prime}$ \\
\hline $11: 40 \mathrm{~h}$ & $11^{0} 15^{\prime}$ & $62^{\circ} 43^{\prime}$ \\
\hline $15: 20 \mathrm{~h}$ & $-58^{0} 01^{\prime}$ & $39^{\circ} 43^{\prime}$ \\
\hline Média anual & $12^{\circ} 28^{\prime}$ & $50^{\circ} 01^{\prime}$ \\
\hline
\end{tabular}

\section{4.- Conclusão}

A inclinação se mostrou diferente dos valores utilizados comercialmente na região de Naviraí. As orientações e o azimute que proporcionou a maior eficiência energética foram de $12^{0} 28^{\prime}$ e $50^{\circ} 01^{\prime}$, respectivamente.

A diferença dos valores em relação ao padrão comercial proporcionou uma melhoria de $16 \%$ na geração de energia.

\section{5.- Bibliografia}

[1] ZEILIK, M.; GAUSTAD, J. Astronomy - The Cosmic Perspective, John Wiley and Sons, New York. 1990.

[2] MORAN, J.M. Climate Studies. Introduction to Climate Sciences. Amer. Meteor. Soc. 525p. 2012.

[3] GOETZBERGER, A.; HEBLING, C.; SCHOCK, H.W. "Photovoltaic Materials, History, Status and Outlook," Materials Science and Engineering. v.40, p.1-46, 2003.

[4] QUEISSER, H. J.; WERNER J. H. Principles and Technology of Photovoltaic Energy Conversion, Solid-State and Integrated Circuit Technology, p. 146-150, 1995,

[5] GRANQVIST, C. G. Transparent conductors as solar energy materials: a panoramic review. Sol. Energy Mater. Sol. Cells. v. 91, p.1529-1598, 2007.

[6] RÜTHER, R.; BRAUN, P. Solar Airports. Refocus, Inglaterra, p.30-34, 2005.

[7] BECKMAN, W.; DUFFIE, J. Solar engineering of thermal processes. 3rd ed. New York: Wiley and Sons. 1980. 
[8] COLLE, S.; PEREIRA, E. B. Atlas de Irradiação Solar do Brasil. Florianópolis: LABSOLARINMET, 1996.

[9] LIU, B.; JORDAN, R. Daily insolation on surfaces tilted towards the equator. Trans ASHRAE. V.67, 1962.

[10] CAMPOS, M. S.; ALCANTARA, L. D. S. Programa para o cálculo da variação da direção de incidência dos raios solares ao longo do ano. COBENGE. 2013.

[11] GOPINATHAN, K. Solar radiation on inclined surfaces. Solar Energy. v.45, 1990.

[12] DAVE, J. Validity of the isotropic distribution approximation in solar energy estimations. Solar Energy. V.19, 1977. 